\title{
Hypoxia Induces Endothelin Gene Expression and Secretion in Cultured Human Endothelium
}

Stella Kourembanas, ** Philip A. Marsden, Lynda P. McQuillan, ${ }^{\star}$ and Douglas V. Faller*

${ }^{*}$ Dana Farber Cancer Institute, ${ }^{\ddagger}$ Joint Program in Neonatology, The Children's Hospital, ${ }^{8}$ The Renal Division and

Department of Medicine, Brigham \& Women's Hospital, Harvard Medical School, Boston, Massachusetts 02115

\begin{abstract}
Hypoxia in vivo is associated with constriction of the distal vasculature in the lung. Uniquely situated at the interface between blood and the vessel wall proper, the vascular endothelium may release vasoactive mediators in the setting of hypoxia. Endothelin-1 is a potent vasoconstrictor released by endothelial cells that could function as a paracrine regulator of vascular tone. We found that physiologic low oxygen tension $\left(\mathrm{Po}_{2}=30\right.$ Torr $)$ increased endothelin secretion from cultured human endothelial cells four to eightfold above the secretion rate at ambient oxygen tension. This increase in secretion was accompanied by a corresponding increase in the transcriptional rate of the preproendothelin gene resulting in increased steadystate mRNA levels of preproendothelin. In contrast, the transcription of a number of other growth-factor-encoding genes, including transforming growth factor- $\beta$, was unaffected by hypoxia. Endothelin transcript production increased within $1 \mathrm{~h}$ of hypoxia and persisted for at least $48 \mathrm{~h}$. In addition, the stimulatory effects of low oxygen tension on endothelin mRNA levels were reversible upon reexposure to $21 \%$ oxygen environments. These findings suggest a role for endothelin in the control of regional blood flow in the vasculature in response to changes in oxygen tension. (J. Clin. Invest. 1991. 88:1054-1057.) Key words: vasoconstrictor • gene regulation • vascular tone • transcriptional regulation $\bullet$ oxygen tension
\end{abstract}

\section{Introduction}

Endothelium-derived relaxing and contracting factors play a key role in modulating vascular smooth muscle tone. Abnormalities in vascular smooth muscle tone and proliferation underlie such diseases as atherosclerosis, pulmonary fibrosis, and persistent pulmonary hypertension of the newborn. Endothelial cells are known to synthesize factors with vasoconstrictive activities. Reports indicate that vasoconstriction of isolated arteries in certain systems is endothelium dependent $(1,2)$, or endothelium enhanced (3). Similarly, vasorelaxation in re-

Address correspondence to Douglas V. Faller, M.D., Ph.D., Dana Farber Cancer Institute, 44 Binney Street, Boston, MA 02115.

Received for publication 14 March 1991 and in revised form 20 May 1991.

J. Clin. Invest.

(c) The American Society for Clinical Investigation, Inc.

$0021-9738 / 91 / 09 / 1054 / 04 \$ 2.00$

Volume 88, September 1991, 1054-1057 sponse to acetylcholine and bradykinin is endothelial dependent $(4,5)$. A critical balance in the production of these potent vasoactive substances would, therefore, be essential in the maintenance of normal vascular tone.

Endothelin is a recently discovered 21-amino acid peptide which was first isolated from the supernatant fraction of cultured endothelial cells and found to have potent vasoactive properties (6). Endothelin represents one member of a family of structurally related peptides. Human endothelin- 1 (ET-1 $)^{1}$ is derived from a 212-amino acid precursor, preproendothelin, via a 38-amino acid intermediate. Endothelin is constitutively expressed by endothelial cells and physiological responses to endothelin are reported for blood vessels derived from a large variety of different tissues including the heart, kidney, and brain (7). Factors shown to induce endothelin production include thrombin (8), transforming growth factor $\beta$, the $\mathrm{Ca}^{2+}$ ionophore A23187, and shear stress (6). The potent effect of endothelin on vascular tone, coupled with the rapid clearance of the circulating peptide, suggests a critical role for locally produced peptide in the regulation of regional blood flow. For the vasculature of the lung, as well as for certain systemic arteries (1), hypoxia is a potent physiologic inducer of local vasoconstriction. We therefore hypothesized that hypoxia might mediate its effects by regulating the release of vasoactive substances, such as endothelin, from endothelial cells. In the studies reported here, early passage cultured endothelium was used to determine the effects of oxygen tension on endothelin production by these cells.

\section{Methods}

Cell culture and conditions for achieving hypoxia. Primary cultures of human umbilical vein endothelial cells were subcultured on gelatincoated plates in the presence of heparin $(15 \mathrm{U} / \mathrm{ml})$ and endothelial cell growth supplement (Sigma Chemical Co., St. Louis, MO) in M199 medium (Gibco Laboratories, Grand Island, NY) with 20\% FCS (HyClone Laboratories, Logan, UT) at $37^{\circ} \mathrm{C}, 5 \% \mathrm{CO}_{2}$ in a humidified incubator. Cells were passaged by trypsinization with $1 \%$ trypsin/ EDTA (Gibco) every 3-4 d. Endothelial cells at confluence were exposed to low oxygen tensions in air-tight chambers flushed with preanalyzed gas mixtures at $37^{\circ} \mathrm{C}$. The desired oxygen mixture $(1 \%$ oxygen, $5 \% \mathrm{CO}_{2}, 94 \% \mathrm{~N}_{2}$ ) was preanalyzed (Northeast Air Gas, Inc., Manchester, NH) and infused periodically into air-tight incubators with inflow and outflow valves (Billups-Rothenberg Inc., Del Mar, CA) at a flow rate of $3 \mathrm{liter} / \mathrm{min}$. The $\mathrm{PO}_{2}$ was measured in the media at multiple time intervals. We found a steady drop in $\mathrm{PO}_{2}$ from 150 Torr to 60 Torr by 6

1. Abbreviations used in this paper: ET-1, endothelin-1; PDGF-A, B, platelet-derived growth factor-A, B. 
h. The $\mathrm{Po}_{2}$ reached a nadir of 30 Torr between 12 and 18 hours of $1 \%$ oxygen infused in the environment and did not fluctuate throughout the remaining incubation period.

RNA analysis. Total cellular RNA was prepared by the method of Chirgwin et al. (9), from endothelial cells exposed to various oxygen tensions at confluence. $15 \mu \mathrm{g}$ of RNA per lane was separated by electrophoresis on $1 \%$ agarose gels containing formaldehyde and transferred to nitrocellulose membranes by blotting. The filters were hybridized with a ${ }^{32} \mathrm{P}$-labeled cDNA probe specific for the human preproendothelin gene (10). The actin probe was the 800 -bp PstI fragment of the mouse $\beta$-actin gene. Hybridization conditions were carried out as previously described (11). For quantitation, transcript levels of preproendothelin were normalized after densitometry to the levels of actin transcripts, which did not change under the various oxygen environments.

Nuclear run-off analysis. Confluent cultures of endothelial cells exposed to $1 \%$ or $21 \%$ oxygen for 6,24 , and $48 \mathrm{~h}$ were lysed and nuclei isolated as described by Kavanaugh et al. (12). $100 \mu \mathrm{l}$ of nuclear suspension were incubated with $0.5 \mathrm{mM}$ each of CTP, ATP, and GTP, and $250 \mu \mathrm{Ci}$ of $\alpha-{ }^{32} \mathrm{P}$-labeled UTP $(3,000 \mathrm{Ci} / \mathrm{mmol})$ (New England Nuclear, Boston, MA). The samples were phenol/chloroform extracted, precipitated, and resuspended at equal $\mathrm{cpm} / \mathrm{ml}$ in hybridization buffer $\left(10-20 \times 10^{6} \mathrm{cpm} / \mathrm{ml}\right)$. Hybridization to denatured probes $(1 \mu \mathrm{g})$ dotblotted on nitrocellulose filters was performed at $40^{\circ} \mathrm{C}$ for $2 \mathrm{~d}$ in the presence of formamide. cDNA probes for the endothelin-1, plateletderived growth factor-A (PDGF-A), sodium-potassium ATPase, and $\beta$-actin genes were used.

Radiobinding assay. To quantify the amount of endothelin secreted by endothelial cells under the various oxygen tensions, conditioned medium was centrifuged at the end of the incubation periods and applied to preactivated Sep-Pak $\mathrm{C}_{18}$ columns. Samples were eluted with ethanol/ $\mathrm{H}_{2} \mathrm{O} /$ acetic acid (90:9.6:0.4), vacuum lyophilized, and resuspended in assay buffer. Determinations of endothelin were performed with a radiobinding assay as previously described by Marsden et al. (13). This competitive radiobinding assay uses rat glomerular microsomes bearing endothelin-specific receptors as the binding fraction and $\left[{ }^{125} \mathrm{I}\right]-\mathrm{ET}-1$ as the radioactive tracer.

\section{Results}

Hypoxia increases preproendothelin $m R N A$ levels in endothelial cells. Primary cultures of human umbilical vein endothelial cells were exposed to a hypoxic atmosphere with $\mathrm{Po}_{2}=30$ $\mathrm{mmHg}$ ( $1 \%$ oxygen) or to an ambient ( $21 \%$ oxygen) environment. Northern blot analysis of endothelial cell RNA after hybridization with a cDNA probe for preproendothelin-1 showed a marked increase in preproendothelin steady state mRNA levels in cells exposed to low oxygen tensions for 24 or $48 \mathrm{~h}$, as compared to $21 \%$ oxygen conditions (Fig. $1 A$ ). Endothelin transcript levels increased twofold within $1 \mathrm{~h}$ of exposure to hypoxia and approximately six to eightfold by $48 \mathrm{~h}$ (Fig. $1 \mathrm{~B}$ ). Return of preproendothelin mRNA to the baseline levels of the normoxic controls was observed within $24 \mathrm{~h}$ of reexposure of cells to a $21 \%$ oxygen environment (Fig. $1 C$ ).

Hypoxia increases the transcriptional rate of endothelin-1. To examine mechanisms by which hypoxia increased endothelin transcript levels, the half-life of the endothelin transcript was determined in the hypoxic and normoxic conditions by actinomycin-D chase experiments. The half-life of the endothelin transcript was $\sim 30$ min under both conditions (data not shown). Hence differential stability of preproendothelin mRNA could not account for the increase in steady-state levels found under varying low oxygen environments. Nuclear runoff analyses were carried out to determine the transcriptional rate of the endothelin gene under hypoxic as compared to nor-

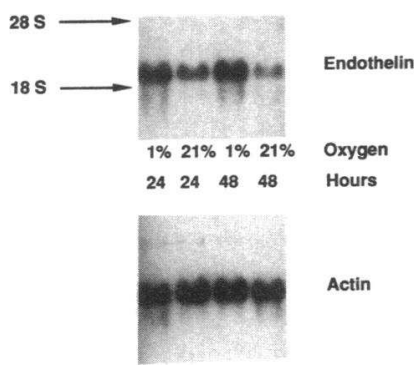

Figure 1. Regulation of preproendothelin mRNA levels by oxygen tension in human umbilical vein endothelial cells. $(A)$ Physiologic levels of hypoxia increase preproendothelin mRNA levels in endothelial cells. Early passage human umbilical vein endothelial cells from at least three different donors were grown to confluence in $1 \%$ gelatin-coated 10 -

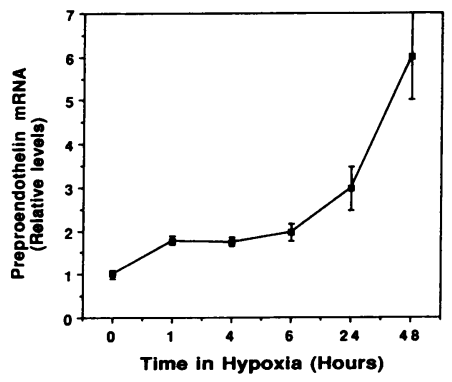

$\mathrm{cm}$ diameter tissue culture plates containing $5 \mathrm{ml}$ of culture media (11). The cells were allowed to reach confluence at $37^{\circ} \mathrm{C}, 5 \%$ $\mathrm{CO}_{2}$ and were then placed in a $21 \%$, or $1 \%$ oxygen environment with $5 \% \mathrm{CO}_{2}$ and the balance $\mathrm{N}_{2}$, for a period of 24 or $48 \mathrm{~h}$. At the end of the 24- and 48-h incubation periods, total cellular RNA was isolated by the method of Chirgwin et al. (9).

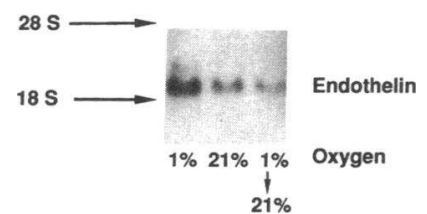
$15 \mu \mathrm{g}$ of RNA per lane were separated by electrophoresis on $1 \%$ agarose gel containing formaldehyde and transferred to nitrocellulose membrane by blotting.

The filter was hybridized with a ${ }^{32} \mathrm{P}$-labeled cDNA probe specific for the human preproendothelin gene (10). Hybridization conditions and stringent washes were carried out as described previously (22). After autoradiography, the filter was stripped and rehybridized with a $\beta$ actin specific probe. $(B)$ Time course of preproendothelin mRNA induction by hypoxia. Endothelial cells were fed with growth medium at least $12 \mathrm{~h}$ before exposure to hypoxia. Total RNA was extracted at time 0 , and after $1,4,6,24$, and $48 \mathrm{~h}$ of exposure of cells to hypoxia, separated on a formaldehyde gel, transferred to nitrocellulose, and hybridized with a ${ }^{32} \mathrm{P}$-labeled ET-1 probe. The partial pressure of oxygen in the medium over the cells was 60-80 Torr for the first $6 \mathrm{~h}$ and decreased to 30 Torr by $24 \mathrm{~h}$, where it remained for the duration of this experiment. Relative preproendothelin transcript levels are plotted against time of exposure of cells to hypoxia. The preproendothelin mRNA levels at $21 \%$ oxygen (time 0 ) were arbitrarily made equal to 1 . The filter was stripped and rehybridized with a $\beta$-actin specific probe, followed by an ATPase specific probe. There were no changes in the transcript levels of either $\beta$-actin or ATPase genes in response to oxygen tension (not shown). (C) The effect of hypoxia on endothelin is reversible. Total cellular RNA was harvested from endothelial cells grown in $1 \%$ or $21 \%$ oxygen environments for $24 \mathrm{~h}$ (lanes 1 and 2 , respectively), and from cells exposed to $1 \%$ oxygen for $24 \mathrm{~h}$ followed by $21 \%$ oxygen for $24 \mathrm{~h}$ (lane 3). Cellular RNA was isolated and transferred to nitrocellulose and the blot was hybridized with a ${ }^{32}$ P-labeled ET-1 specific probe and then stripped and rehybridized with a $\beta$-actin specific probe. $\beta$-actin transcript levels remained the same under all conditions (not shown). 
moxic conditions. Transcriptional rates were determined at 6 , 24 , and $48 \mathrm{~h}$ after exposure to $21 \%$ or $1 \%$ oxygen $\left(\mathrm{Po}_{2}=30\right.$ $\mathrm{mmHg}$ ) atmosphere. Transcriptional rates of other genes expressed by endothelial cells such as VWF, sodium-potassium ATPase, PDGF-A, and $\beta$-actin were analyzed for comparison. In five separate experiments, hypoxia stimulated transcription of the endothelin gene an average of four to eightfold above the rate observed at $21 \%$ oxygen (Fig. 2). The transcriptional rates of the ATPase, vWF, and PDGF-A genes were not increased by hypoxia. In two out of five experiments, the gene for $\beta$-actin was transcribed at a rate two to three times higher in cells exposed to hypoxic compared to normoxic conditions. (The steady-state mRNA levels of $\beta$-actin, however, remained constant under all oxygen environments.) The hypoxia-induced increase in preproendothelin mRNA in human umbilical vein endothelial cells is therefore predominantly due to increased gene transcription as opposed to enhanced stability of its mRNA transcript.

Hypoxia-mediated increases in endothelin secretion. To determine whether this four to eightfold increase in gene transcription resulted in corresponding increases in endothelin protein secreted by endothelial cells, a radioligand binding assay was used to quantitate the endothelin content in conditioned media. After exposing endothelial cells to hypoxia, conditioned media were collected at 1-h, 3-h, 6-h, 12-h, and 24-h intervals in parallel with media from cells exposed to ambient atmospheres. The media were assayed for endothelin activity as described under Methods, and compared between the two conditions at each of the indicated time points. A representative result from four independent experiments is shown on Fig. 3. The amount of secreted endothelin increased four to eightfold when cells were incubated in low oxygen atmospheres as compared to $21 \%$ oxygen conditions. This effect was demonstrable within $6 \mathrm{~h}$ of exposure to hypoxia. Incubation periods shorter than $6 \mathrm{~h}$ yielded no detectable differences in endothelin secretion between the two oxygen environments. It is possible that differences in secretion of endothelin occur substantially faster than $6 \mathrm{~h}$, but the constraints of our system are such that enough endothelin must be secreted by $10^{6}$ cells to change the concentration in $5 \mathrm{ml}$ of overlying medium before it can be detected. Although the radioreceptor assay used here cannot distinguish among the different endothelin isotypes (ET-1, -2, -3), the cDNA probe used in the hybridization experiments recognizes

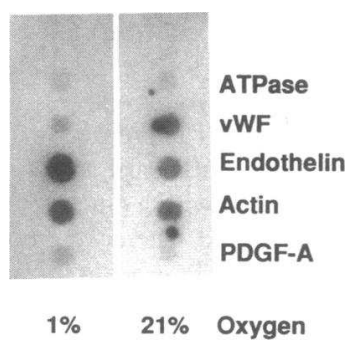

Figure 2. Hypoxia increases endothelin gene transcription. Endothelial cells at confluence were exposed to $1 \%$ or $21 \%$ oxygen environments for 6,24 , and $48 \mathrm{~h}$ as described in the legend to Fig. 1. Nuclei were isolated as described previously $(15,21)$, and in vitro transcription was allowed to resume in the presence of $\alpha{ }^{32}$ P-UTP. Equal amounts of ${ }^{32} \mathrm{P}$-labeled, in vitro transcribed RNA were hybridized to

denatured cDNA for the endothelin-1, PDGF-A, sodium-potassium ATPase, and $\beta$-actin genes, which had been previously immobilized on nitrocellulose filters. Shown are representative autoradiograms from nuclear transcription after $6 \mathrm{~h}$ of exposure to $1 \%$ or $21 \%$ oxygen, from five separate experiments. Similar results are obtained after 24 or $48 \mathrm{~h}$ of exposure to hypoxia.

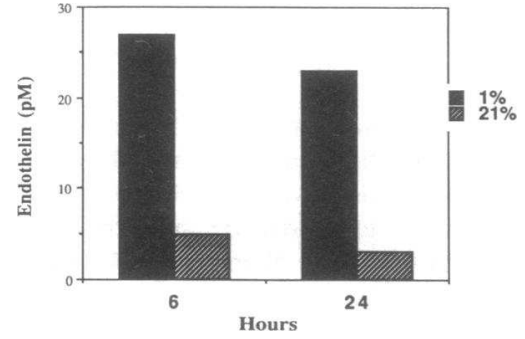

Figure 3. Hypoxia increases the secretion of endothelin from cultured endothelial cells. Media conditioned by human umbilical vein endothelial cells under normoxic ( $21 \%$ oxygen; hatched bars) or hypoxic ( $1 \%$ oxygen; solid bars) conditions were

collected at the indicated times. Determinations of endothelin were performed with a radiobinding assay as previously described (13). Recovery of ET- 1 was $\geq 90 \%$. Inter- and intraassay variability are $11.7 \%$ and $6.0 \%$, respectively. After removal of the conditioned media, the cells were lysed and total protein was quantified to normalize for any differences in cell survival. Equal amounts of total cellular protein were obtained under hypoxic and normoxic conditions for each time point, suggesting that this period of hypoxia had no toxic effects on the endothelial cells. Endothelin production is shown as endothelin concentration in $5 \mathrm{ml}$ of medium produced/time.

only the gene for ET-1 and does not cross-react with the others. In addition, the vascular endothelium appears to express ET-1 only (14). Therefore, hypoxia-induced increases in endothelium production by endothelial cells are due to increases in ET-1.

\section{Discussion}

Endothelin is a potent vasoconstrictor and also a mitogen for fibroblasts and smooth muscle cells $(15,16)$. Increases in its secretion from endothelial cells can, therefore, increase the contractile and proliferative state of the underlying fibroblasts and smooth muscle cells. Hypoxia has been reported to have a variety of effects on endothelial cells, ranging from alterations in protein synthesis to changes in gene transcription (17-22). For example, Vender et al. (18) reported the release of a unique smooth muscle cell mitogen from bovine pulmonary endothelial cells exposed to hypoxia. Humphries et al. (19) showed that hypoxia causes a decrease in the secretion of heparan sulfate proteoglycan from cultures of bovine pulmonary artery endothelial cells. We have reported that PDGF-B chain gene expression is dramatically increased in endothelial cells exposed to a narrow and physiologic range of low oxygen tension $\left(\mathrm{PO}_{2}\right.$ $=20-45 \mathrm{mmHg})(22)$.

Hypoxia also has been reported to result in the release of vasoactive substances from whole vessels. Rakugi et al. (23) reported a stimulation of endothelin release of $70 \%$ above baseline in response to hypoxia in a mesenteric artery perfusate system. Vanhoutte et al. (24) using a bioassay system also found evidence of endothelin-like mediated vasoconstriction in response to hypoxia. In the studies reported here, hypoxia was found to increase endothelin production by endothelial cells principally by increasing the transcriptional rate of the gene within $1 \mathrm{~h}$ of exposure to low oxygen tension. The maximal increase was four to eightfold above the baseline rate of transcription present at ambient atmospheres. A comparable increase was shown for the amount of total endothelin protein secreted by these cells within $6 \mathrm{~h}$ after hypoxic exposure. The endothelial cells continued to proliferate during exposure to 
hypoxia, and continued to express transcripts for other growth factors like transforming growth factor $\beta$, PDGF-A, basic fibroblast growth factor, and structural proteins like $\beta$-actin (22). Furthermore, endothelin production returned to baseline levels upon reexposure of cells to normoxia suggesting that the cellular response to hypoxia was not mediated by cellular toxicity. The increase in gene transcription among the growth factors tested was limited to the vasoconstrictors (endothelin and PDGF-B) produced by endothelial cells.

In contrast to PDGF-B which was induced $24 \mathrm{~h}$ after hypoxic exposure, however, increases in endothelin production occurred within $1 \mathrm{~h}$ of hypoxia and lasted for a period of at least 2-3 d (longer exposure times were not examined). Indeed, not only is the response time of the endothelin gene to hypoxia much faster than for the PDGF-B gene, but its expression is increased at milder degrees of hypoxia. The physical constraints of the experimental systems we employ in these studies result in a substantial delay period before the oxygen tension in the media bathing the endothelial cells equilibrates with the surrounding gas mixture. As a result, the $\mathrm{PO}_{2}$ in the media is about 60-80 Torr after $1 \mathrm{~h}$ of exposure of cells to $1 \%$ oxygen atmospheres. Yet, this period of time and mild degree of hypoxia is sufficient to increase endothelin transcript levels. A more severe degree of hypoxia, namely a $\mathrm{PO}_{2}$ of $20-45$ Torr, was necessary to induce the PDGF-B gene.

The endothelial cells exhibit a two-phase response to hypoxia stimuli in their secretion of vasoactive agents. The sensitive and rapid regulation of endothelin expression in response to environmental oxygen makes it a likely candidate as an important regulator of regional blood flow in response to acute changes in oxygen tension. Hypoxia-induced contractions of pulmonary artery strips occur at least 2-6 $\mathrm{h}$ after an adaptation at $\mathrm{PO}_{2}$ of $20-40$ Torr (1). Factors such as endothelin that are secreted within $6 \mathrm{~h}$ of hypoxia could mediate such vasoconstrictive events. PDGF-B, with its later induction requiring more severe degrees of hypoxia, may then be a more important modulator of the smooth muscle hypertrophy and architectural remodeling occurring in chronic hypoxia. Both processes, vasoconstriction and smooth muscle cell hyperplasia, are critical to the pathogenesis of diseases such as atherosclerosis, pulmonary fibrosis, and pulmonary hypertension.

\section{Acknowledgments}

We thank Dr. Merton Bernfield for critical review of the manuscript.

Dr. Kourembanas was supported by a grant from the American Lung Association. Dr. Faller was supported by research grants from the American Cancer Society, The National Institutes of Health, and The Council for Tobacco Research. Dr. Kourembanas is the recipient of a Clinical Investigator Award and a Charles H. Hood/Medical Foundation Fellowship. Dr. Marsden is a Medical Research Council of Canada fellowship recipient. Dr. Faller is the recipient of a Senior Faculty Award from the American Cancer Society.

\section{References}

1. Holden, W. E., and E. McCall. 1984. Hypoxia-induced contractions of porcine pulmonary artery strips depend on intact endothelium. Exp. Lung Res. 7:101-112.
2. Rubanyi, G. M., and P. M. Vanhoutte. 1985. Hypoxia releases a vasoconstrictor substance from the canine vascular endothelium. J. Physiol. (Lond.). 364:45-56.

3. Brenner, B. M., J. L. Troy, and B. J. Ballerman. 1989. Endothelium-dependent vascular responses. Mediators and mechanisms. J. Clin. Invest. 84:13731378.

4. Furchgott, R. F., and J. V. Zawadzki. 1980. The obligatory role of endothelial cells in the relaxation of arterial smooth muscle by acetylcholine. Nature (Lond.). 288:373-376.

5. Palmer, R. M. J., A. G. Ferrige, and S. Moncada. 1987. Nitric oxide release accounts for the biological activity of endothelium-derived relaxing factor. $\mathrm{Na}$ ture (Lond.). 327:524-526.

6. Yanagisawa, M., H. Kurihara, S. Kimura, Y. Tomobe, M. Kobayashi, Y. Mitsui, Y. Yazaki, K. Goto, and T. Masaki. 1988. A novel potent vasoconstrictor peptide produced by vascular endothelial cells. Nature (Lond.). 332:411-415.

7. MacCumber, M. W., C. A. Ross, B. M. Glaser, and S. H. Snyder. 1989. Endothelin: visualization of mRNAs by in situ hybridization provides evidence for local action. Proc. Natl. Acad. Sci. USA. 86:7285-7289.

8. Moon, D. G., M. J. Horgan, T. T. Andersen, S. R. Krystek, Jr., J. W. Fenton II, and A. B. Malik. 1989. Endothelin-like pulmonary vasoconstrictor peptide release by $\alpha$-thrombin. Proc. Natl. Acad. Sci. USA. 86:9529-9533.

9. Chirgwin, J. M., A. E. Przybyla, R. J. MacDonald, and W. J. Rutter. 1979. Isolation of biologically active ribonucleic acid from sources enriched in ribonuclease. Biochemistry. 18:5294-5299.

10. Itoh, Y., M. Yanagisawa, S. Ohkubo, C. Kimura, T. Kosaka, A. Inoue, N. Ishida, Y. Mitsui, H. Onda, M. Fujino, and T. Masaki. 1988. Cloning and sequence analysis of cDNA encoding the precursor of a human endothelium-derived vasoconstrictor peptide, endothelin: identity of human and porcine endothelin. FEBS (Fed. Eur. Biochem. Soc.) Lett. 231:440-444.

11. Kourembanas, S., and D. V. Faller. 1989. Platelet-derived growth factor production by human umbilical vein endothelial cells is regulated by basic fibroblast growth factor. J. Biol. Chem. 264:4456-4459.

12. Kavanaugh, W. M., G. R. Harsh IV, N. F. Starksen, C. M. Rocco, and L. T. Williams. 1988. Transcriptional regulation of the A and B chain genes of platelet-derived growth factor in microvascular endothelial cells. J. Biol. Chem. 263:8470-8472.

13. Marsden, P. A., D. M. Dorfman, T. Collins, B. M. Brenner, S. H. Orkin, and B. J. Ballermann. 1991. Regulated expression of endothelin-1 in bovine glomerular endothelial cells. Am. J. Physiol. 261 (Renal Fluid Electrolyte Physiol. 30). F117-F125.

14. Yanagisawa, M., and T. Masaki. 1989. Endothelin, a novel endotheliumderived peptide. Pharmacological activities, regulation and possible roles in cardiovascular control. Biochem. Pharmacol. 38:1877-1883.

15. Komuro, I., H. Kurihara, T. Sugiyama, F. Takaku, and Y. Yazaki. 1988. Endothelin stimulates c-fos and c-myc expression and proliferation of vascular smooth muscle cells. FEBS (Fed. Eur. Biochem. Soc.) Lett. 238:249-252.

16. Nakaki, T., M. Nakayama, S. Yamamoto, and R. Kato. 1989. Endothelinmediated stimulation of DNA synthesis in vascular smooth muscle cells. Biochem. Biophys. Res. Commun. 158:880-883.

17. Ogawa, S., H. Gerlach, C. Esposito, A. Pasagian-Macaulay, J. Brett, and D. Stern. 1990. Hypoxia modulates the barrier and coagulant function of cultured bovine endothelium. Increased monolayer permeability and induction of procoagulant properties. J. Clin. Invest. 85:1090-1098.

18. Vender, R. L., D. R. Clemmons, L. Kwock, and M. Friedman. 1987. Reduced oxygen tension induces pulmonary endothelium to release a pulmonary smooth muscle cell mitogen(s). Am. Rev. Respir. Dis. 135:622-627.

19. Humphries, D. E., S.-L. Lee, B. L. Fanburg, and J. E. Silbert. 1986. Effects of hypoxia and hyperoxia on proteoglycan production by bovine pulmonary artery endothelial cells. J. Cell. Physiol. 126:249-253.

20. Sciandra, J., J. Subjeck, and C. Hughes. 1984. Induction of glucose-regulated proteins during anaerobic exposure and of heat-shock proteins after reoxygenation. Proc. Natl. Acad. Sci. USA. 81:4843-4847.

21. Heacock, C., and R. Sutherland. 1986. Induction characteristics of oxygen regulated proteins. J. Radiat. Oncol. Biophys. 12:1287-1290.

22. Kourembanas, S., R. L. Hannan, and D. V. Faller. 1990. Oxygen tension regulates the expression of the platelet-derived growth factor-B chain gene in human endothelial cells. J. Clin. Invest. 86:670-674.

23. Rakugi, H., Y. Tabuchi, M. Nakamaru, M. Nagano, K. Higashimori, H. Mikami, T. Ogihara, and N. Suzuki. 1990. Evidence for endothelin-1 release from resistance vessels of rats in response to hypoxia. Biochem. Biophys. Res. Commun. 169:973-977.

24. Vanhoutte, P. M., W. Auch-Schwelk, C. Boulanger, P. A. Janssen, Z. S. Katusic, K. Komori, V. M. Miller, V. B. Schini, and M. Vidal. 1989. Does endothelin-1 mediate endothelium-dependent contractions during anoxia? J. Cardiovasc. Pharmacol. 13(Suppl 5):S124-128. 